\title{
Appearance and Transient Expression of Oxytocin Receptors in Fetal, Infant, and Peripubertal Rat Brain Studied by Autoradiography and Electrophysiology
}

\author{
Eliane Tribollet, ${ }^{1}$ Serge Charpak, ${ }^{1}$ Anne Schmidt, ${ }^{2}$ Michel Dubois-Dauphin, ${ }^{1}$ and Jean Jacques Dreifuss ${ }^{1}$ \\ 'Department of Physiology, University Medical Center, Geneva, Switzerland, and "CNRS-INSERM, Center of \\ Pharmacology-Endocrinology, Montpellier, France
}

The development of oxytocin (OT) receptors in the rat brain and spinal cord was studied by in vitro light microscopic autoradiography and by electrophysiology. OT receptors were labeled using a monoiodinated OT antagonist in tissue sections from animals aged between embryonic day 12 (E12) and postnatal day 90 (PN90); the response of ongoing spike activity to the addition of OT was assessed in neurons located in the dorsal motor nucleus of the vagus nerve of the neonate.

Specific binding was detected first at E14 in a region that later differentiated into the dorsal motor nucleus of the vagus nerve. Many other regions were progressively labeled between E20 and PN5. From PN5 to PN16, the distribution of binding sites remained essentially unchanged but differed markedly from that characteristic of the adult. The changeover from the "infant pattern" to the "adult pattern" occurred in 2 stages: the first change took place between PN16 and PN22, a time corresponding to the preweaning period; the second change occurred after PN35 and thus coincided with the onset of puberty. During the first transition period, binding was reduced or disappeared in several areas intensely labeled at earlier stages, in particular, in the cingulate cortex and the dorsal hippocampus. At the same time, binding sites appeared in the ventral hippocampus. At puberty, high densities of OT binding sites appeared in the ventromedial hypothalamic nucleus and the olfactory tubercle.

Electrophysiological activity was recorded from vagal neurons in slices obtained from animals sacrificed at PN1-PN12. OT and a selective OT agonist reversibly increased the firing rate of these neurons in a concentration-dependent manner. The neuronal responsiveness was similar to that reported previously in the adult. These results suggest that OT binding sites detected by autoradiography in the developing rat brain represent, at least in some areas, functional neuronal receptors.

\footnotetext{
Received July 22, 1988; revised Oct. 24, 1988; accepted Oct. 26, 1988.

This work was supported in part by Grant 3.358.0.86 from the Swiss National Foundation. We wish to thank Mrs. A. Marguerat and M. Berti for excellent technical assistance, Dr. M. Manning (Toledo, $\mathrm{OH}$ ) for the gift of the oxytocin structural analogs, Dr. S. Jard and C. Barberis (Montpellier) for providing the iodinated form of the oxytocin antagonist and for helpful discussions, and Dr. M. Raggenbass, F. Loup, and J. Z. Kiss for their critical review of the manuscript.

Correspondence should be addressed to Eliane Tribollet, $\mathrm{Ph} . \mathrm{D}$., Department of Physiology, University Medical Center, 9 Av. de Champel, 1211 Geneva 4, Switzerland.

Copyright (c) 1989 Society for Neuroscience $0270-6474 / 89 / 051764-10 \$ 02.00 / 0$
}

The classical hormonal effects of oxytocin (OT) released from the hypothalamoneurohypophyseal axons are well established. In addition, $O T$ is also present in axons projecting to various areas within the CNS (Sofroniew, 1985), which suggests that it may play a neurotransmitter or neuromodulator role. Additional evidence for such a role includes its release under experimental conditions in situ and in vitro (Buijs, 1983), its effect on the electrical activity of single neurons in the brain (Mühlethaler et al., 1983, 1984; Charpak et al., 1984), the fact that small amounts of OT injected into the brain or the cerebral ventricles modulate neuroendocrine and autonomic functions (Freund-Mercier and Richard, 1984; Rogers and Herman, 1985), as well as the presence of high-affinity binding sitcs for ${ }^{3} \mathrm{H}-\mathrm{OT}$ within the brain (Audigier and Barberis, 1985; De Kloet et al., 1985; Van Leeuwen et al., 1985; Freund-Mercier et al., 1987; Tribollet et al., 1988a). Displacement studies using unlabeled OT or synthetic structural analogs possessing high receptor specificity suggested that the central OT binding sites are identical or similar to those found in the uterus and the mammary gland (Elands et al., 1988a).

The ontogeny of OT has been investigated using both radioimmunoassay and immunocytochemistry (Whitnall et al., 1985; Alstein and Gainer, 1988; Alstein et al., 1988). These studies have shown that OT is dectectable only after birth in the rat brain, whereas OT precursor and $\mathrm{CH}$-terminal elongated OTs are present from E16 onwards. The developmental stages of OT innervation and of OT receptors in the brain is essentially unknown.

In the present work, we have studied the pattern of pre- and postnatal development of binding sites for OT in the rat brain using light microscopic autoradiography and a newly available radioligand, ${ }^{125} \mathrm{I}-\mathrm{d}\left(\mathrm{CH}_{2}\right)_{5}\left[\mathrm{Tyr}(\mathrm{Me})^{2}, \mathrm{Thr}^{4}, \mathrm{Tyr}\left(\mathrm{NH}_{2}\right)^{9}\right] \mathrm{OVT}$, hereafter called ${ }^{125} \mathrm{I}$-OTA. This compound is superior to ${ }^{3} \mathrm{H}$-OT in terms of specific activity, aftinity, and selectivity for OT binding sites (Elands et al., 1988b). We compared the distribution and the affinity of OT binding sites in the rat brain and spinal cord at various stages of development, ranging from fetal to adult animals. We also show by means of electrophysiology that OT binding sites in the neonate represent functional receptors. A preliminary report of some of these findings has been presented (Tribollet et al., 1988b).

\section{Materials and Methods}

Autoradiography. Rats from a Sprague-Dawley derived strain were used at various embryonic (E14-E20) and postnatal time points (PN1-PN90). E0 was the day at which a copulation plug was observed in the mother. The gestation lasted 22 or $23 \mathrm{~d}$. 

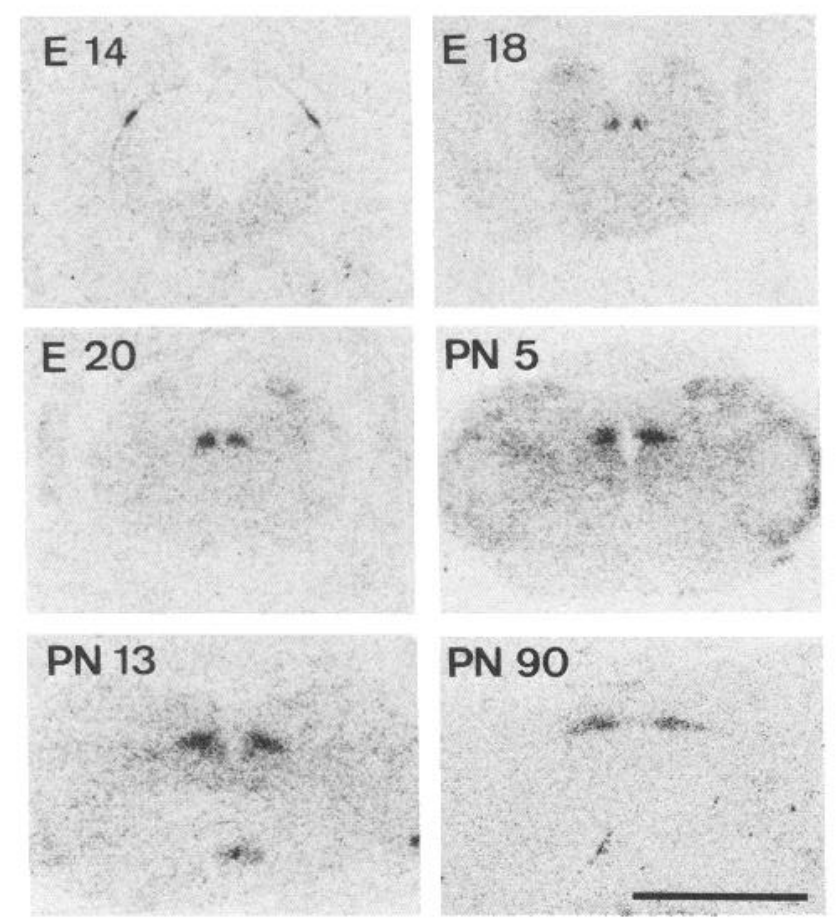

Figure 1. First appearance of OT binding sites and their persistence until adulthood in the dorsal motor nucleus of the vagus nerve. Each photograph represents a transverse section of the brain stem at the different stages indicated (see Materials and Methods). In this and in Figures 4-6, $E$, embryonic day; $P N$, postnatal day. Scale bar, $2 \mathrm{~mm}$.

Fifty-eight animals were used for the distribution studies. Four animals were used at each of the following ages: E12, 14, 16, 18, 20, and PN1; 2 animals for PN3, 5, 10, 13, 16, 19, 22, 25, 30, 35, 40, 45; 5 animals for PN60 and PN90. The sex of the embryos was not determined, and male rats were used otherwise. Frozen brain and spinal cord sections ( $15 \mu \mathrm{m}$ thick) were cut from the whole embryos up to PN1 and from dissected brain and spinal cord in older rats. Sections were thawmounted on gelatin-coated slides, dried, and stored until use at $-80^{\circ} \mathrm{C}$. Prior to the binding procedure, all slides were dipped $5 \mathrm{~min}$ in a solution of $0.2 \%$ paraformaldehyde in PBS ( $\mathrm{pH} 7.4$ ), then rinsed twice in $50 \mathrm{~mm}$ TRIS- $\mathrm{HCl}(\mathrm{pH}$ 7.4). This light fixation does not alter the binding but gives better preservation of the nervous tissue, in particular, in fetal and newborn animals. Incubation was carried out for $1 \mathrm{hr}$ at room temperature in a humid chamber by covering each slide with $400 \mu \mathrm{l}$ of the incubation medium ( $50 \mathrm{~mm}$ TRIS- $\mathrm{HCl}, 0.1 \mathrm{~mm}$ Bacitracin, $5 \mathrm{~mm} \mathrm{MgCl}$, $0.1 \%$ bovine serum albumin) containing $0.05 \mathrm{~nm}^{125}$ I-OTA. Nonspecific binding was evaluated by incubating adjacent sections with medium containing in addition $1 \mu \mathrm{M}$ OT. Incubation was followed by 2 washes in ice-cold incubation medium and a quick rinse in distilled water. The slides were rapidly dried and apposed to Kodak X-OMat AR film for $5 \mathrm{~d}$. Films were developed in Kodak D19, and the sections were stained with cresyl violet. To describe sites of labeling, we used the nomenclature of Paxinos and Watson (1986).

In order to compare the binding characteristics of the immature brain to those of the adult brain, 8 additional rats were used. In 4 animals, two 10-d-old and two 90-d-old, adjacent sections were cut through regions containing high densities of OT binding sites, the cingulate cortex in the infant, the ventral subiculum, and the ventromedial nucleus of the hypothalamus in the adult: One series of sections was incubated with ${ }^{125}$ I-OTA at a concentration of $0.07 \mathrm{~nm}$; the others with the same concentration of ${ }^{125}$ I-OTA and increasing concentrations of OT, i.e., $0.25,0.5,1,2.5,5,10,20,50,75,100$, and $500 \mathrm{~nm}$. In 4 other animals, again 2 at PN10 and 2 at PN90, series of adjacent sections were incubated with ${ }^{125}$ I-OTA at $0.05 \mathrm{~nm}$ and with ${ }^{125} \mathrm{I}$-OTA at $0.2 \mathrm{~nm}$, in order to assess whether low-affinity binding sites could be detected at any stage.

Electrophysiology. Experiments were performed on brain slices from 33 rats at ages PN1-PN12. After decapitation, the skull was opened and the whole brain excised. A block of brain and cerebellum was prepared and its rostral surface glued on the stage of a vibrating microtome. One or two coronal slices, $500 \mu \mathrm{m}$ thick, containing the dorsal motor nucleus of the vagus nerve were obtained from each animal. The slices were transferred to a thermoregulated recording chamber (33$34^{\circ} \mathrm{C}$ ) and placed on a Nylon net at the interface between a humidified atmosphere and a perifusion medium containing $130 \mathrm{~mm} \mathrm{NaCl}, 5 \mathrm{~mm}$ $\mathrm{KCl}, 20 \mathrm{~mm} \mathrm{NaHCO}, 10 \mathrm{~mm}$ glucose, $1.25 \mathrm{~mm} \mathrm{KH}_{2} \mathrm{PO}_{4}, 2 \mathrm{~mm} \mathrm{MgSO}_{4}$, and $2.4 \mathrm{mM} \mathrm{CaCl}_{2}$, which was gassed with $95 \% \mathrm{O}_{2}$ and $5 \% \mathrm{CO}_{2}(\mathrm{pH}$ 7.35-7.45).

Intracellular recordings were performed using glass micropipettes filled with potassium acetate $(3 \mathrm{M}, \mathrm{pH} 7.4)$ and having tip d.c. resistances of 60-120 M $\Omega$. Voltage signals were amplified, displayed on an oscilloscope, and stored on magnetic tape. The membrane potential and rate meter records of cell firing were monitored on a chart recorder. In order to assess their effect, OT, vasopressin, or synthetic structural analogs were dissolved in the medium and perifused at $7 \mathrm{ml} / \mathrm{min}$.

In several experiments, micropipettes were filled with Lucifer yellow ( $5 \%$ in $0.3 \mathrm{M} \mathrm{LiCl}$ ) to mark the neurons from which recordings had been obtained and to assess their location. The fluorescent dye was injected by passing negative current pulses through the pipette $(0.25 \mathrm{nA}, 250$ $\mathrm{msec}, 1 \mathrm{~Hz}$ ) for $5 \mathrm{~min}$. Slices were then fixed for $12 \mathrm{hr}$ in $4 \%$ paraformaldehyde and thereafter immersed in a $30 \%$ sucrose solution. Sections, $60 \mu \mathrm{m}$ thick, were cut in a cryostat, mounted on gelatin-coated slides, counterstained with ethidium bromide, and observed with an epifluorescence microscope to locate the injected neuron.

Chemicals. OT and vasopressin were purchased from Bachem (Bubendorf, Switzerland). The OT antagonists desGly $\left(\mathrm{NH}_{2}\right)-\mathrm{d}\left(\mathrm{CH}_{2}\right)_{5}$ $\left[\mathrm{Tyr}(\mathrm{Me})^{2}, \mathrm{Thr}^{4}\right] \mathrm{OVT}$ and $\mathrm{d}\left(\mathrm{CH}_{2}\right)_{5}\left[\mathrm{Tyr}(\mathrm{Me})^{2}, \mathrm{Thr}^{4}, \mathrm{Tyr}\left(\mathrm{NH}_{2}\right)^{2}\right] \mathrm{OVT}$, and the selective OT agonist $\mathrm{OH}\left[\mathrm{Thr}^{4}, \mathrm{Gly}^{7}\right] \mathrm{OT}$ were synthetized and kindly provided by $\mathrm{M}$. Manning (Toledo, $\mathrm{OH}$ ). The synthesis and pharmacology of the OT antagonists are described in Manning et al. (1989). $\mathrm{d}\left(\mathrm{CH}_{2}\right)_{5}\left[\mathrm{Tyr}(\mathrm{Me})^{2}, \mathrm{Thr}^{4}, \mathrm{Tyr}\left(\mathrm{NH}_{2}\right)^{9}\right] \mathrm{OVT}$ was radioiodinated on the tyrosine in position 9 by S. Jard, C. Barberis, A. Schmidt, and J. Elands (Montpellier, France) to yield ${ }^{125}$ I-OTA (Elands et al., 1988b). Lucifer yellow was purchased from Fluka (Buchs, Switzerland).

\section{Results}

\section{Appearance and distribution of OT binding sites in the fetal and the infant rat brain}

The first specific OT binding sites to be detected in the CNS, observed at E14, were located in the posterior dorsal neural tube. The presence of the binding in 2 thin lateral bands (Fig. 1) suggested that they were located on a still-migrating group of cells that later forms the dorsal motor nucleus of the vagus nerve. At E16, the neural tube was almost completely closed, and the labeling was now located in 2 cell groups on each side of the midline, which by E18, could be clearly identified as the dorsal motor nuclei of the vagus nerve on sections counterstained with cresyl violet. This nucleus was thereafter found labeled at all ages examined and remained labeled, though less intensely, in the adult (Fig. 1).

Other labeled structures were progressively observed from E20 onwards. The anterior olfactory nucleus, the caudate putamen, the nucleus accumbens, and the mammillary complex were detectable at E20; the dorsal subiculum, the para- and presubiculum, the cingulate cortex, the reticular nucleus, the substantia gelatinosa of the spinal trigeminal nucleus (pars caudalis) and of the spinal cord at PN1; and the bed nucleus of the stria terminalis, some septal, thalamic and amygdaloid nuclei, and the dorsal peduncular cortex, as well as the retrosplenial cerebral cortex at PN3. A faint and diffuse but specific labeling was also clearly visible throughout the hypothalamus and amygdala at PN5.

From PN5 to PN13-PN16, the distribution of OT binding sites remained unchanged, while the density of binding tended to increase in all labeled structures and to reach a maximum around PN10-PN13. This distribution, characteristic of the infant brain is illustrated in Figure 2. 
A

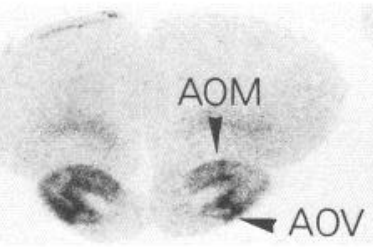

B

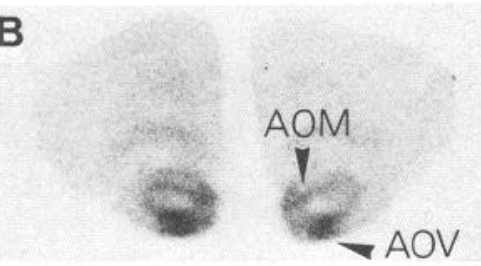

C
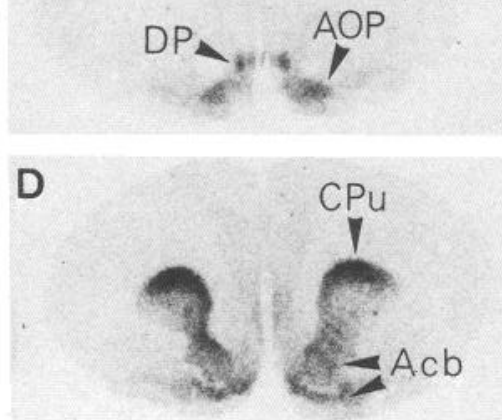

E

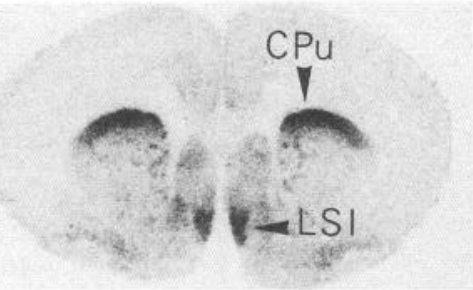

$\mathbf{F}$
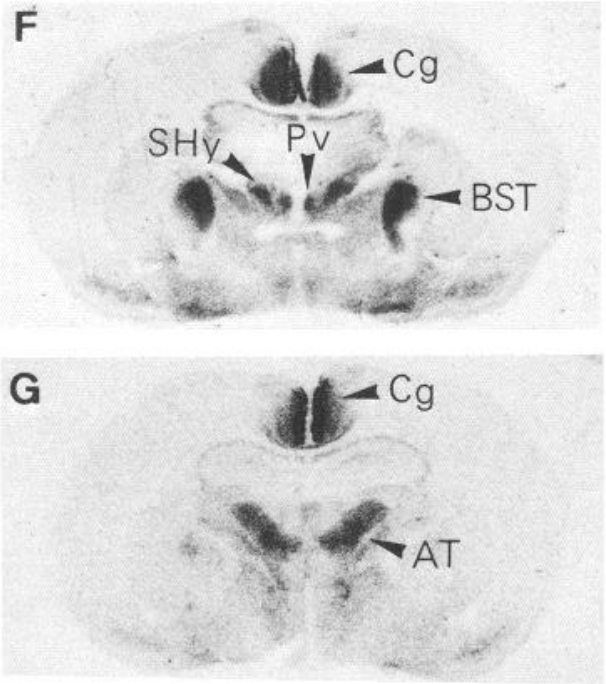

H

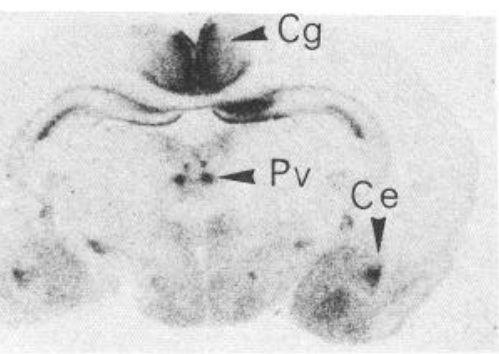

I

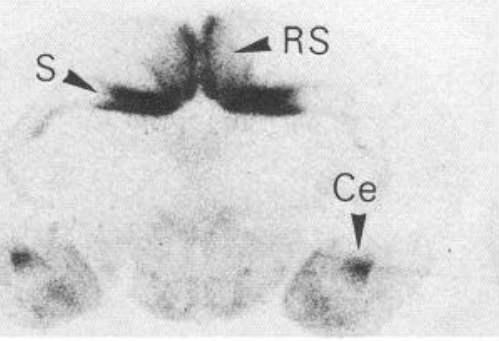

J

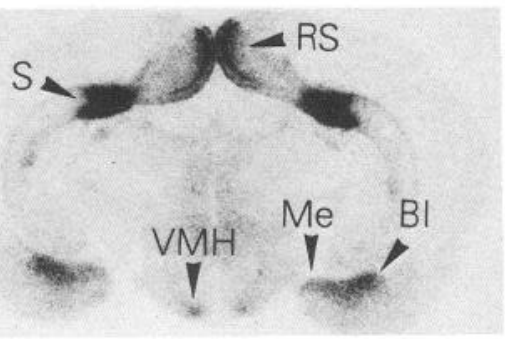

K

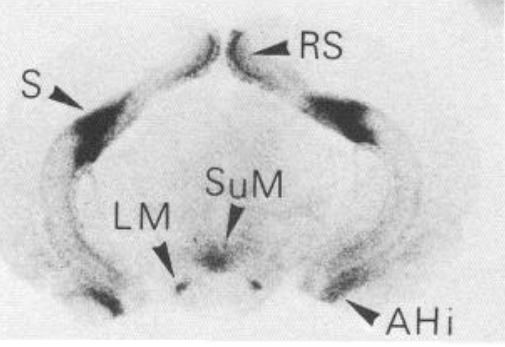

L
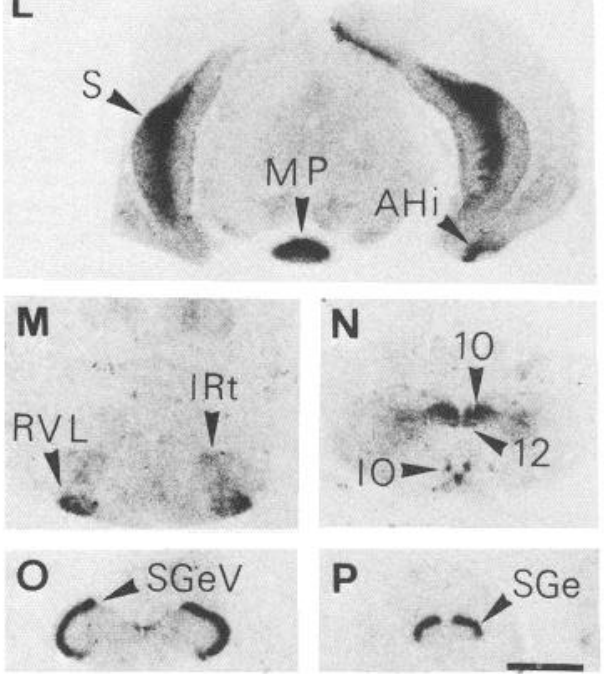

Figure 2. Map of OT binding sites in the rat brain at PN10. Autoradiographs were obtained from coronal sections. $A-P$ display all rostrocaudal levels of the brain in which specific labeling was detected. The following abbreviations are used in this figure and in Figure 3 and $7: A c b$, accumbens nucleus; $A H i$, amygdalohippocampal area; $A O M$, anterior olfactory nucleus, medial; $A O P$, anterior olfactory nucleus, posterior; $A O V$, anterior olfactory nucleus, ventral; $A T$, anterior thalamus; $B L$, basolateral amygdaloid nucleus; $B S T$, bed nucleus of the stria terminalis; $C A 1$, field CA1 of Ammon's horn; $C e$, central amygdaloid nucleus; $C P u$, caudate putamen; $C g$, cingulate cortex; $D P$, dorsal peduncular nucleus; $E n t$, entorhinal cortex; $I C j$, islands of Calleja; $I O$, inferior olive; $I R t$, intermediate reticular nucleus; $L M$, lateral mammillary nucleus; $L S$, lateral septum nucleus; $L S I$, lateral septem nucleus, intermediate; $M e$, medial amygdaloid nucleus; $P a S$, parasubiculum; $P R h$, perirhinal cortex; $P r S$, presubiculum; $P V$, paraventricular thalamic nucleus; $R S$, retrosplenial cortex; $R V L$, rostroventral reticular nucleus; $S$, subiculum; $S G e$, substantia gelatinosa (spinal cord); $S G e V$, substantia gelatinosa (spinal trigeminal nucleus, caudal); $S H y$, septohypothalamic nucleus; $S u M$, supramammillary nucleus; $V M H$, ventromedial hypothalamic nucleus; $V P$, ventral pallidum; 10, dorsal motor nucleus of the vagus nerve; 12 , hypoglossal nucleus. Scale bar, 2 mm.

\section{Comparison between the distribution of OT receptors in the infant and in the adult rat brain}

Figures 2 and 3 permit a comparison to be made of the distribution of OT binding sites at PN10 and PN90, respectively. Some areas were labeled at both times, although the density of the binding varied slightly; the anterior olfactory nucleus, the dorsal peduncular cortex, the amygdaloid complex, and the dorsal motor nucleus of the vagus nerve belong to this category. In many other areas, striking differences were observed on comparing infant (PN10) and adult (PN90) brain. In several areas, expression of receptors was only transient. On the contrary, in other areas, receptors were evidenced only in the adult. Finally, in a few structures, receptors were not localized in the adult in the same subdivision as in the young.

The changeover from the "infant pattern" to the "adult pattern" was not progressive but occurred rather abruptly in 2 stages: The first transformation took place during the third postnatal week, which corresponds to the preweaning period; the second took place after PN35, which is the time of onset of puberty.

During the first transition period, a large decrease or a complete disappearance of binding occurred in several areas. Thus, the cingulate cortex was intensely labeled before PN16; labeling was hardly detectable at PN19 and became undetectable thereafter (Fig. 4). The same holds true for the substantia gelatinosa 
A

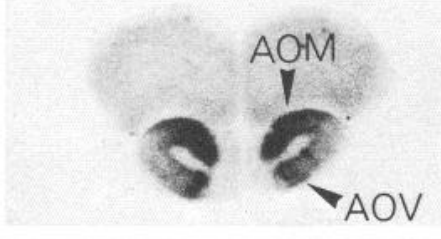

B
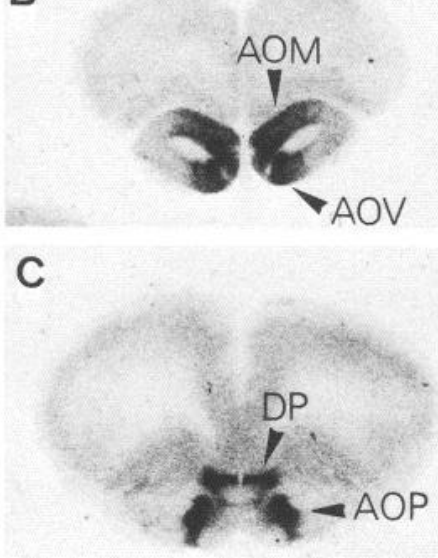

D

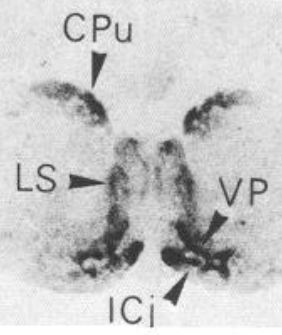

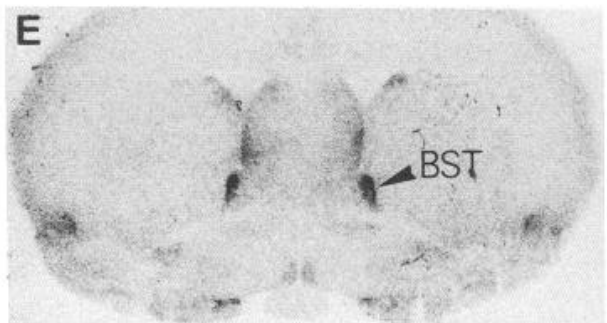
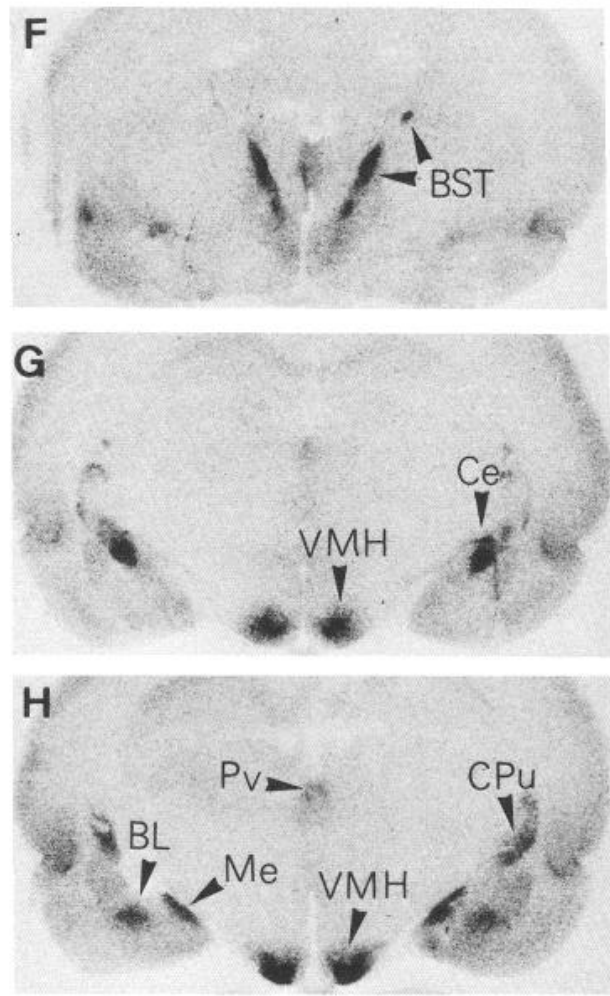

I

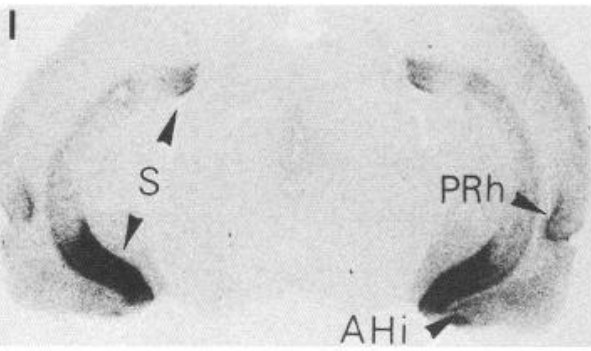

J
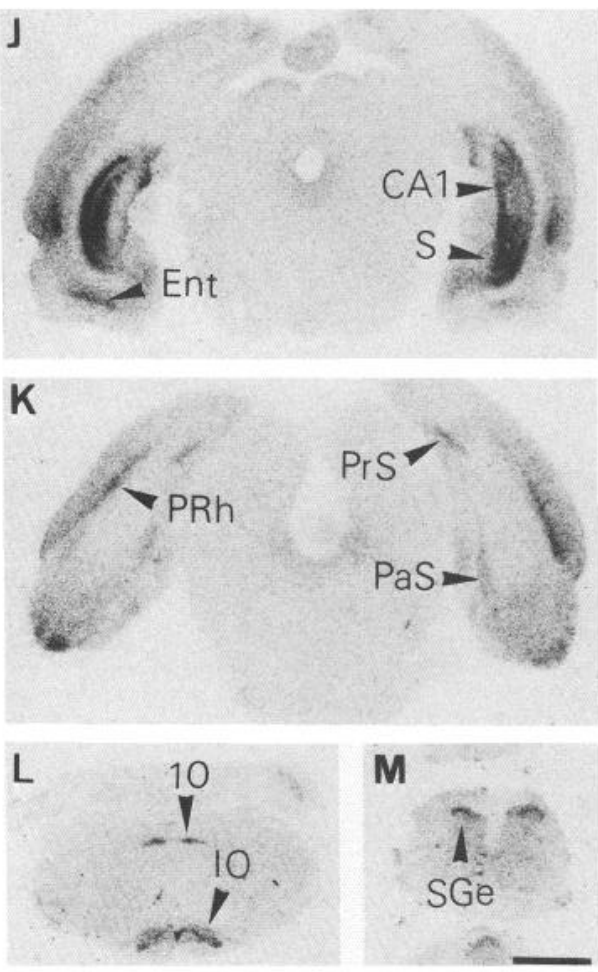

Figure 3. Map of OT binding sites in the adult rat brain (PN90). Autoradiographs were obtained from coronal sections. $A-L$ display all rostrocaudal levels of the brain in which specific labeling was detected. For abbreviations, see Figure 2 . Scale bar, $2 \mathrm{~mm}$.

of the spinal trigeminal nucleus and of the spinal cord, the accumbens nucleus, the caudate putamen, the anterior and paraventricular thalamic nuclei, the mammillary complex, and the reticular nucleus, which were all intensely labeled in the young but faintly labeled if at all in the adult. The diffuse hypothalamic and amygdaloid labeling disappeared between PN19 and PN22. A different phenomenon took place during the same transition period in the hippocampus and in the bed nucleus of the stria terminalis. In the hippocampus, the disappearance of binding in the dorsal subiculum was accompanied by the concomitant appearance of binding in the ventral subiculum (Fig. 5). In the bed nucleus of the stria terminalis, OT receptors appeared evenly distributed in the young (Fig. $2 F$ ) but were restricted to its medial component in the adult (Fig. 3, E, F).

The "adult pattern" (as shown in Fig. 3) was established between PN19 and PN22, with notable exceptions, however. In the olfactory tubercle, i.e., the Calleja islands and cell groups of the ventral pallidum, and in the hypothalamic ventromedial nucleus, the binding was almost undetectable until PN40 and reached its adult pattern around PN60 only. Figure 6 shows the marked increase of labeling that occurs in the hypothalamic ventromedial nucleus between PN40 and PN45. At the same time, in the olfactory tubercle, the islands of Calleja and other cell groups probably belonging to the ventral pallidum (Switzer et al., 1982) began to be labeled (Fig. $3 D$ ).

\section{Comparison of the affinity characteristics of infant and adult $O T$ receptors}

The affinity of the OT binding sites present in the infant brain was compared with that of the sites present in the adult brain by means of competition experiments. In sections through the cingulate cortex and the thalamus of 2 animals at age PN10 and through the ventromedial nucleus of the hypothalamus and the ventral subiculum of 2 adult rats (PN90), the binding of ${ }^{125} \mathrm{I}-$ OTA was progressively displaced by OT at increasing concentrations. Representative photographs (Fig. 7) show a similar inhibition of ${ }^{125}$ I-OTA binding in nervous tissue from the infant and from the adult brain. The percentage of label displaced at all concentrations of OT tested in the cingulate cortex at PN10 did not differ markedly from the displacement of label in 2 areas of the adult brain, the ventromedial nucleus of the hypothalamus and the ventral subiculum (Table 1).

The question whether the transient nature of the binding observed in several areas during development could be due to a 

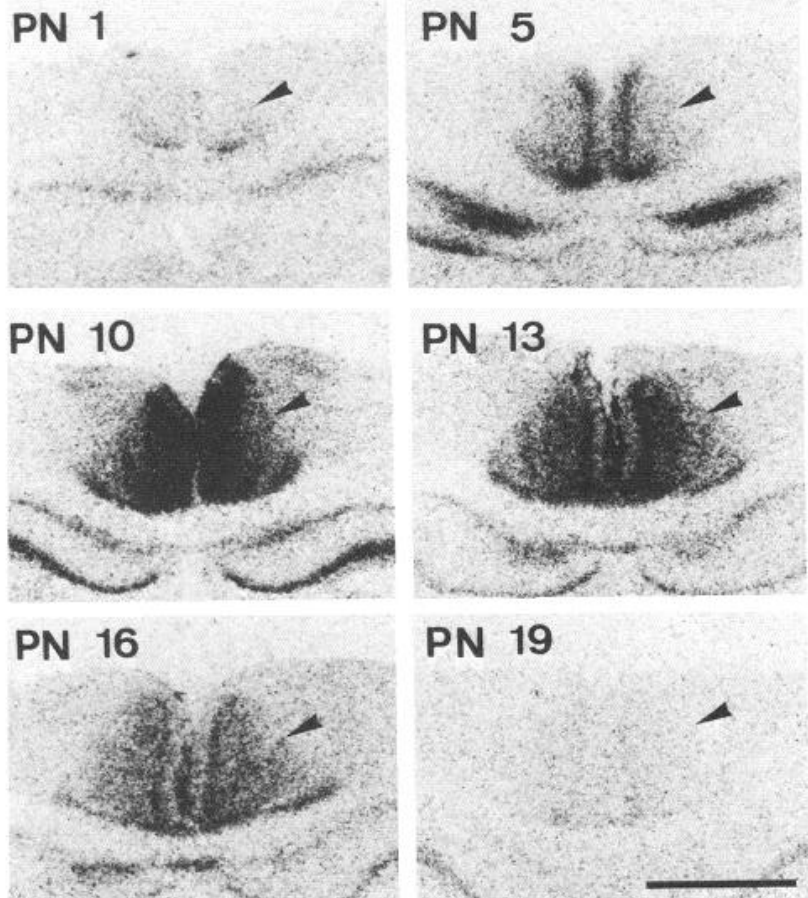

Figure 4. Transient expression of OT binding sites in the cingulate cerebral cortex (arrow) and the neighboring dorsal hippocampus. Autoradiographs are shown from coronal sections taken at the same anteroposterior level at the developmental ages indicated. Scale bar, $2 \mathrm{~mm}$.

decrease in the affinity of the receptors later in development rather than to an arrest of receptor synthesis was ascertained by incubating sections from 10 -d-old and adult animals with ${ }^{125} \mathrm{I}$ OTA at $0.2 \mathrm{nM}$, i.e., at a concentration 4 times greater than usual. In this situation, the nonspecific binding was increased, but both in the infant and adult, the distribution of specific binding sites did not differ from that observed with $0.05 \mathrm{nM}$ of ${ }^{125}$ I-OTA.

\section{Electrophysiological evidence that OT binding sites detected in the neonate are functional neuronal receptors}

The question whether OT binding sites present at birth represent functional receptors was addressed by electrophysiological means. To this end, stable intracellular recordings were obtained from 44 vagal neurons in slices from animals at ages PN1-PN12. Neurons had a resting membrane potential more negative than $-50 \mathrm{mV}$. Twenty of these neurons were spontaneously active $(0.8 \pm 0.2$ spikes $/ \mathrm{sec}$, mean \pm SEM $)$. They fired action potentials with a mean amplitude of $54 \pm 1 \mathrm{mV}$; their mean membrane input resistance was $223 \pm 21 \mathrm{M} \Omega$, and they possessed the transient voltage-dependent potassium current $I_{\mathrm{A}}$ characteristic of adult vagal neurons in guinea pig (Yarom et al., 1986) and rat (S. Charpak, unpublished observations).

OT reversibly excited 42 of these neurons, the remaining 2 being unaffected. Whenever Lucifer yellow was injected $(n=7)$, the labeled neuron was located within the boundaries of the dorsal motor nucleus of the vagus nerve (see Fig. 8). An effect of OT was detectable from the day of birth (Fig. 9A). The threshold for the increase in the firing rate was approximately $10^{-10}$ $\mathrm{M}$, the effect being maximal at about $10^{-7} \mathrm{M}$ (Fig. $9 \mathrm{~B}$ ). This effect was associated with a membrane depolarization which amounted to $1.0 \pm 0.3 \mathrm{mV}$ at $10^{-9} \mathrm{M}($ mean $\pm \mathrm{SEM}, n=8), 2.6 \pm 0.3$
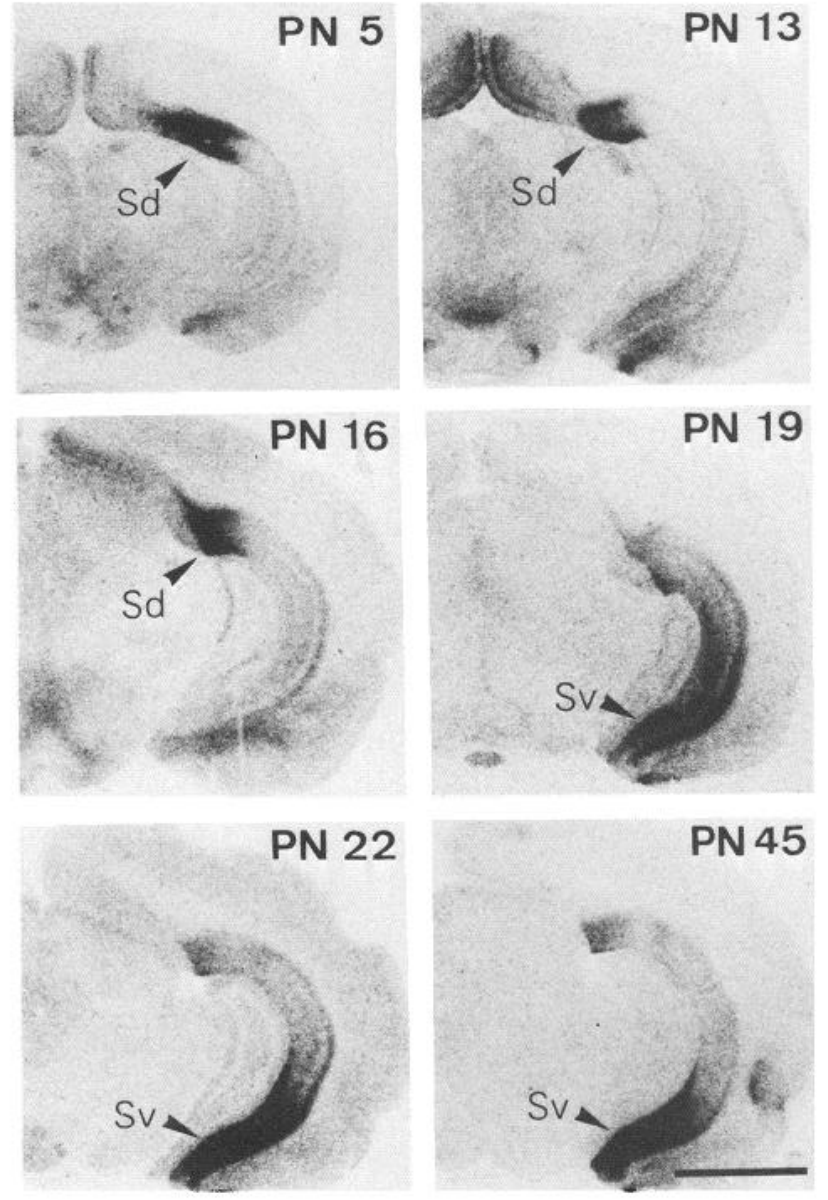

Figure 5. OT binding sites are reduced in the dorsal subiculum $(S d)$ and concomitantly appear in the ventral subiculum $(S v)$. Same format as Figure 4. Scale bar, $2 \mathrm{~mm}$.

$\mathrm{mV}$ at $10^{-8} \mathrm{M}(n=10), 4.1 \pm 0.6 \mathrm{mV}$ at $10^{-7} \mathrm{M}(n=11)$, and $5.1 \pm 1.3 \mathrm{mV}$ at $10^{-6} \mathrm{M}(n=6)$. OT caused no obvious change in action potential shape or membrane input resistance. The response to OT could be suppressed by equivalent concentrations of the OT antagonist desGly $\left(\mathrm{NH}_{2}\right)-\mathrm{d}\left(\mathrm{CH}_{2}\right)_{5}$ [Tyr(Me $)^{2}$,$\left.\mathrm{Thr}^{4}\right]$ OVT $\left(10^{-8}-5.10^{-8} \mathrm{M} ; n=6\right)$ and mimicked by $\mathrm{OH}\left[\mathrm{Thr}^{4}\right.$,Gly $\left.{ }^{7}\right] \mathrm{OT}$. At $10^{-8} \mathrm{M}$, this selective OT agonist induced an increase in firing rate $(3 \pm 1.2$ spikes/sec; $n=3)$ similar to that caused by the same concentration of oxytocin $(2.5 \pm 0.7$ spikes/ sec; $n=5$ ). On the other hand, vasopressin at the same concentration of $10^{-8} \mathrm{M}$ had a significantly weaker effect than OT $(1.3 \pm 0.6$ spikes/sec; $n=5, p<0.05$, Student's $t$ test).

\section{Discussion}

In the present study, we have used autoradiography to detect the first appearance of OT binding sites in the fetal rat brain and to follow their pattern of distribution throughout development to adulthood. Binding sites first appeared at E14 in a region that later differentiates into the dorsal motor nucleus of the vagus nerve. The functional responsiveness of these binding sites was ascertained by showing that vagal neurons were excited by OT in the neonate brain. The distribution of OT binding sites was shown to undergo major reshaping during postnatal development. 

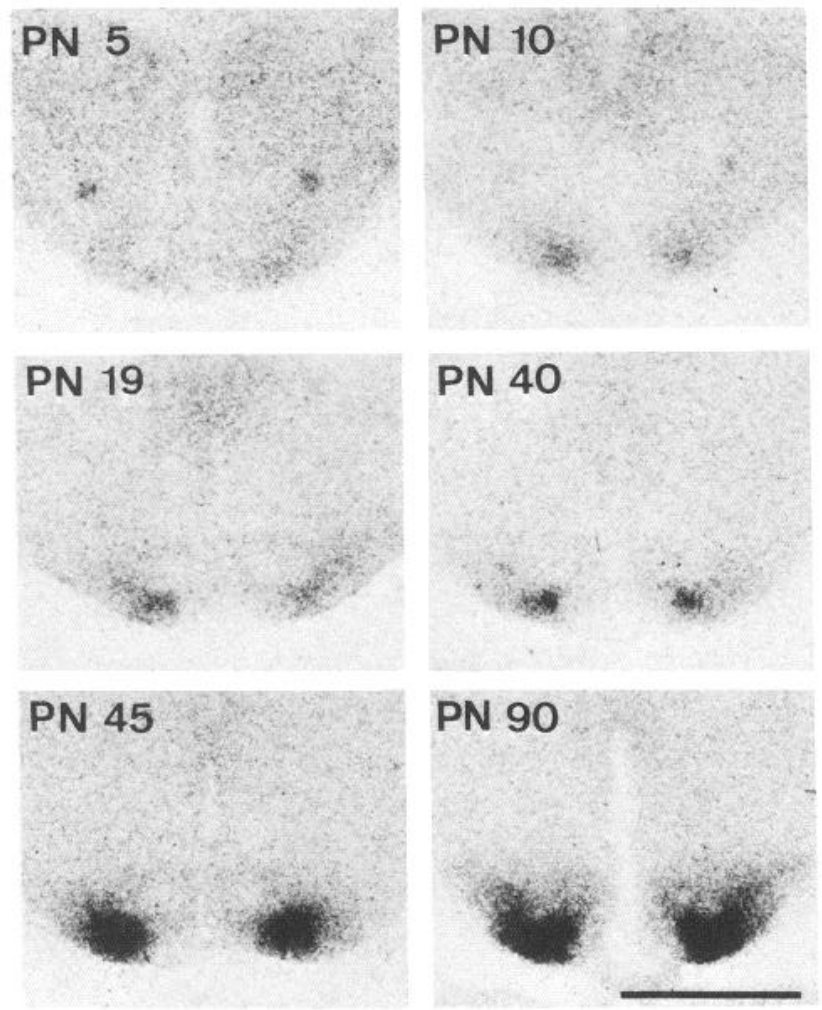

Figure 6. Late appearance of OT binding sites in the hypothalamic ventromedial nucleus. Autoradiographs were obtained from coronal sections cut at the level of the posterior part of the nucleus at the developmental ages indicated. Scale bar, $2 \mathrm{~mm}$.

\section{Methodological considerations}

The iodinated OT antagonist used in this study to detect OT binding sites has been shown to possess several advantages compared to ${ }^{3} \mathrm{H}-\mathrm{OT}$ (Elands et al., 1988b). It has a higher specific activity (2000 vs $50-70 \mathrm{Ci} / \mathrm{mmol})$ and a higher affinity for uterine (dissociation constants $=0.05$ vs $1.0 \mathrm{nM}$ ) and brain OT receptors (dissociation constants $=0.07$ vs $2 \mathrm{nM}$ ). In addition, it is more selective for OT receptors than OT itself. When using this ligand at an appropriate concentration (close to the dissociation constant, i.e., $0.05 \mathrm{nM}$ ), we found in the adult rat brain (Fig. 3), after 3-5 d of exposure time, a distribution of specific OT binding sites generally similar to that we observed with ${ }^{3} \mathrm{H}$ OT after 3-4 months of exposure (Tribollet et al., 1988b). Moreover, due to the more favorable ratio of specific/nonspecific binding, some additional structures could be detected which were either very faintly labeled by ${ }^{3} \mathrm{H}-\mathrm{OT}$, in particular, the medial and basolateral amygdaloid nuclei (Fig. $3 H$ ), the dorsal motor nucleus of the vagus nerve, and the inferior olive (Fig. $3 L$ ), as well as the substantia gelatinosa of the trigeminal nucleus and spinal cord (Fig. $3 M$ ). It thus appears that with this ligand autoradiography allows the detection of very low densities of OT binding sites.

Comparison between the infant OT receptor and the adult OT receptor

OT binding sites detected in the infant brain appear to be similar to those present in the adult rat brain according to several criteria.

First, the binding of ${ }^{125}$ I-OTA could be displaced by low con-
Table 1. Displacement of specific ${ }^{125}$ I-OTA $(0.07 \mathrm{nM})$ binding by increasing concentrations of oxytocin (OT) in the brain of 2 infant (PN10) and 2 adult (PN90) rats

\begin{tabular}{llll}
\multirow{2}{*}{$\begin{array}{l}\text { OT } \\
\text { concentration } \\
\text { (nM) }\end{array}$} & \multicolumn{3}{l}{${ }^{125}$ I-OTA binding $(\% \text { of control })^{a}$} \\
\cline { 2 - 4 } & PN10 & $\begin{array}{l}\text { PN90 } \\
\text { VMH }^{b}\end{array}$ & $\begin{array}{l}\text { PN90 } \\
\text { Subiculum }\end{array}$ \\
\hline 0 & 100 & 100 & 100 \\
0.25 & 96 & 92 & 94 \\
0.5 & 83 & 88 & 86 \\
1 & 70 & 74 & 74 \\
2.5 & 56 & 62 & 66 \\
5 & 43 & 56 & 53 \\
10 & 36 & 42 & 34 \\
20 & 19 & 25 & 28 \\
50 & 11 & 13 & 14 \\
75 & 5 & 9 & 6 \\
100 & 1 & 2 & 3 \\
500 & 0 & 0 & 1 \\
\hline
\end{tabular}

${ }^{a}$ Optical density was measured on circular areas of $0.3 \mathrm{~mm}$ of diameter. Twenty measurements ( 10 per animal) were averaged. Each value on the table is expressed as percentage of the optical density determined in the absence of OT.

${ }^{n} \mathrm{VMH}$, ventromedial nucleus of the hypothalamus.

centrations of unlabeled OT at PN10 in the same way as at PN90 (Fig. 7, Table 1). This indicates that the affinity of the OT receptor in the immature brain apparently does not differ from its affinity in the brain of the adult. The $\mathrm{IC}_{50}$ estimated from the data of Table 1 is approximately $5 \mathrm{~nm}$ at both PN10 and PN90. This value is close to the theoretical $\mathrm{IC}_{50}$ for the OT receptor in the hippocampus of the adult rat, which is equal to $4 \mathrm{nM}$, according to the formula $\mathrm{IC}_{50}=K_{i}\left[1+\left(H / K_{d}\right)\right]$, where $\mathrm{IC}_{50}$ is the concentration of OT displacing $50 \%$ of the specific binding of ${ }^{125}$ I-OTA; $H$, the concentration of ${ }^{125}$ I-OTA, and $K_{i}$ and $K_{d}$, the dissociation constants of OT (Audigier and Barberis, 1985) and ${ }^{125}$ I-OTA (Elands et al., 1988b), respectively.

Second, no additional structures could be labeled by increasing the concentration of ${ }^{125}$ I-OTA from 0.05 to $0.2 \mathrm{nM}$, which indicates that, in both the infant and the adult, only high-affinity binding sites are detected. Therefore, the binding observed in the infant brain that disappears at weaning in all likelihood reflects a disappearance of receptor expression rather than a reduction in the affinity for the ligand.

Third, in slices obtained from the brain stem of neonatal rats, OT excited neurons located in the dorsal motor nucleus of the vagus nerve. As in the adult, the neural response in the neonate consisted of a membrane depolarization associated with an increase in firing rate. The structure-activity characteristics of this electrophysiological response were those of "adult" OT receptors (Charpak et al., 1984; Raggenbass et al., 1987). These electrophysiological data corroborate those of Suzue et al. (1981), who observed a membrane depolarization induced by OT in the spinal cord of neonatal rats.

Taken together, our results suggest that OT binding sites detected by autoradiography in the developing rat CNS (1) are similar to those detected in the adult rat brain and (2) probably represent functional neuronal receptors, at least in some areas. Similar studies have yet to be carried out in the cingulate cortex or dorsal subiculum of the immature animal, where binding sites are expressed only transiently. 

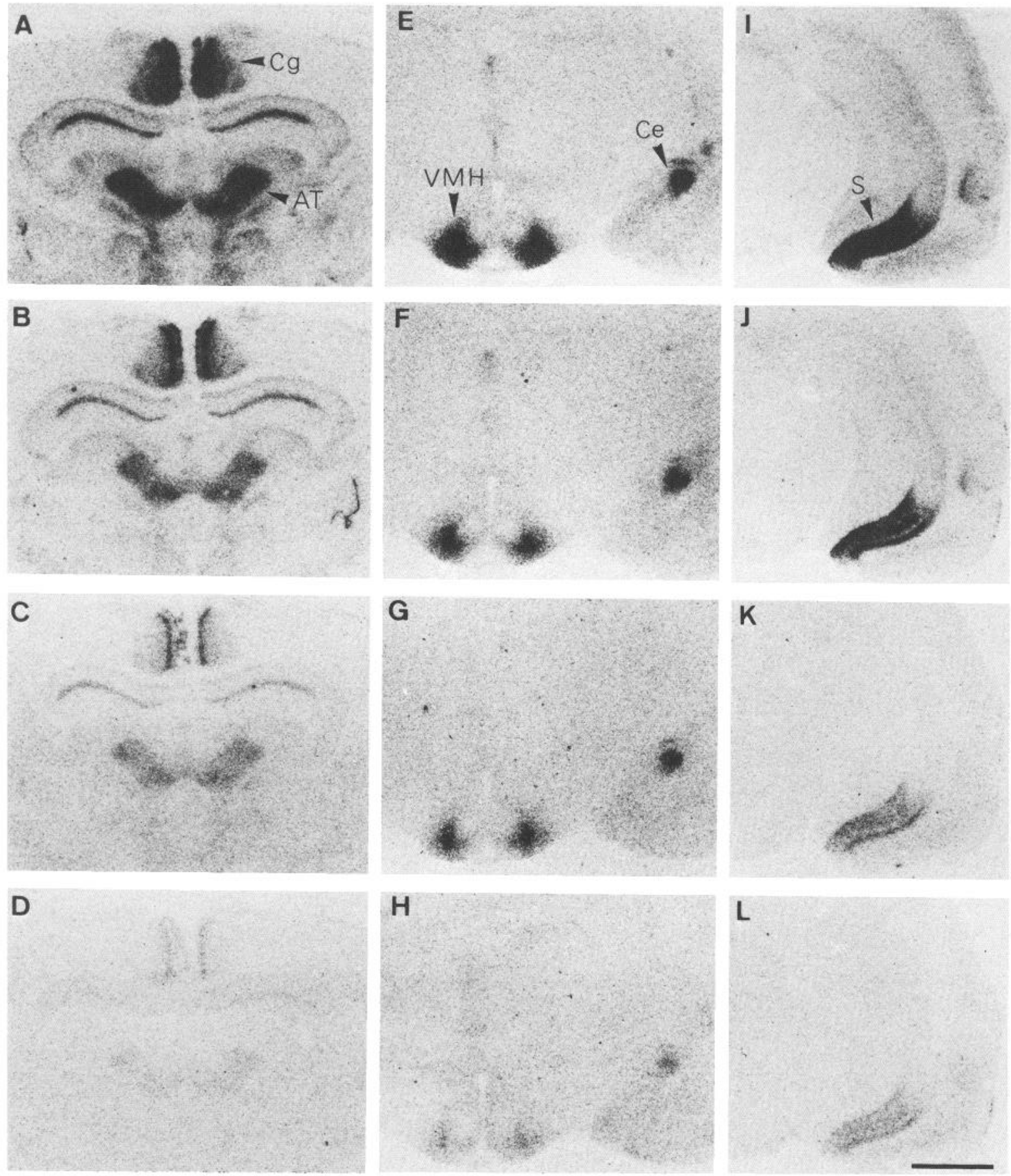

Figure 7. Displacement of ${ }^{125}$ I-OTA binding by various concentrations of OT. Autoradiographs were obtained from alternate frontal sections cut through the cingulate cortex and thalamus of a $10 \mathrm{~d}$ old rat $(A-D)$ and through the hypothalamic ventromedial nucleus or the ventral subiculum of an adult at age PN90 ( $E-H$ and $I-L$, respectively). $A, E$, and $I$ illustrate the labeling obtained with 0.07 nM ${ }^{125}$ I-OTA alone. Other photographs show the progressive decrease in the intensity of labeling when sections were incubated with the same concentration of ${ }^{125} \mathrm{I}$-OTA and in addition with OT at $1 \mathrm{~nm}(B, F$, and $J), 10 \mathrm{~nm}(C, G$, and $K)$, and $50 \mathrm{~nm}(D, H$, and $L)$. Scale bar, $2 \mathrm{~mm}$.

\section{Relation between the development of $O T$ receptors and the development of OT immunoreactivity}

Receptors for OT were first detected during fetal life in the brain stem at E14, i.e., before any immunoreactive OT is detectable in the brain of the rat fetus. Using radioimmunoassay, Alstein and Gainer (1988) showed that only the OT precursor and C-terminal extended forms of OT are present in the brain before birth. The OT precursor was first detected at day E16, while the active, amidated form of OT was assayable only after birth. These results are in agreement with immunocytochemical data, which showed that OT neurons cannot be stained before birth with antibodies directed against OT, whereas they can be stained from E19 with antibodies directed against the OT-associated neurophysin (Buijs et al., 1980; Whitnall et al., 1985). Therefore, the expression of OT binding sites in the dorsal motor nucleus 
A
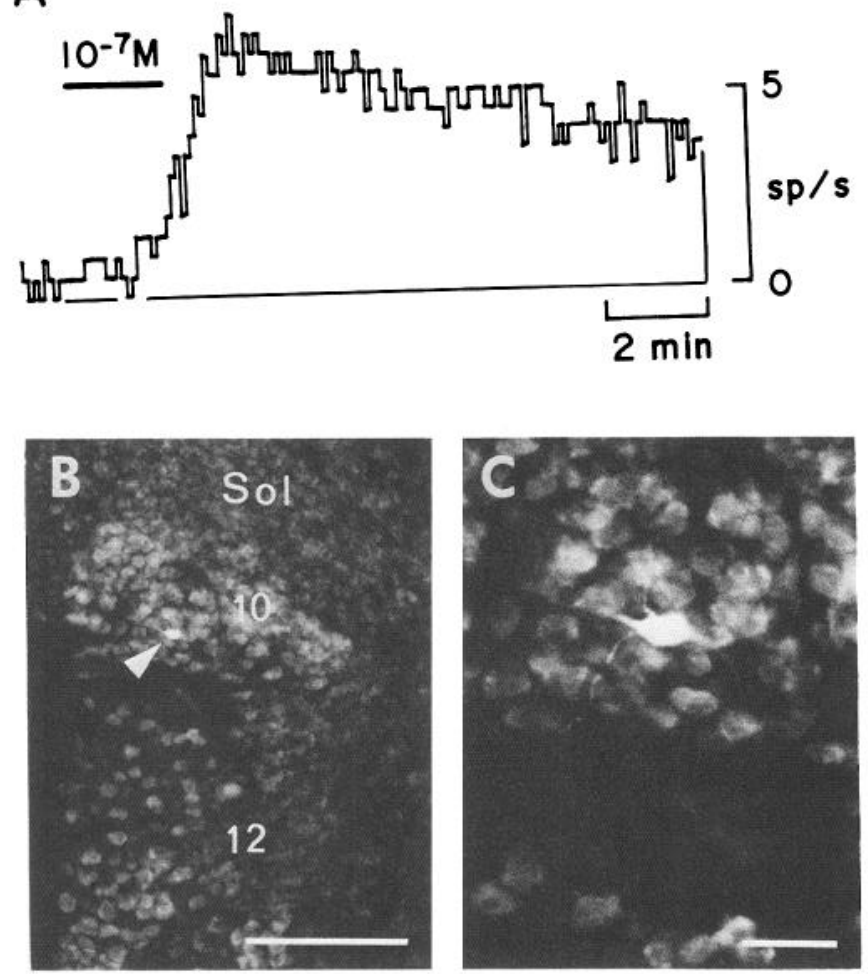

Figure 8. Localization of an OT-sensitive neuron in a slice from a rat sacrificed at age PN9. $A$, Ratemeter record. OT, at $10^{-7} \mathrm{M}$, applied for 2 min caused an increase in rate of firing. $B$ and $C$, Photographs of the area from which recording $A$ was obtained. The neuron injected with Lucifer yellow is shown at low magnification $(B$, arrowhead) and high magnification $(C)$, respectively. It is a large multipolar cell belonging to the dorsal motor nucleus of the vagus nerve $(10)$, a densely packed cluster of neurons that lies dorsally to the hypoglossal nucleus (12) and ventrally to the nucleus of the solitary tract ( $\mathrm{Sol}$ ). Scale bars: B, 200 $\mu \mathrm{m} ; C, 50 \mu \mathrm{m}$.

of the vagus nerve and other areas before birth is apparently independent of, and precedes the occurrence of, the active form of the peptide. This raises the question of the biological significance, if any, of these sites and of the nature of their endogenous ligand. Whether vasopressin, which is present in its active form from E16 onwards (Alstein and Gainer, 1988), or the extended C-terminal forms of OT could act as endogenous ligands has yet to be investigated. Preliminary studies suggest that the C-terminus-extended OTs are extremely weak agonists when tested on the firing of vagal neurons. With respect to the ontogeny of OT-containing pathways, a report described the absence of any OT-immunoreactive fibers at birth in the rat brain, while vasopressin-immunoreactive fibers were already detected in the brain stem at E20 (Buijs et al., 1980). To our knowledge, no information is available in print on the development of innervation of OT after birth.

\section{Expression of transient $O T$ receptors}

The transient expression of OT receptors in several areas of the neonate and infant rat brain is intriguing. Similar high amounts of receptor labeling around PN10 and their progressive disappearance during the third postnatal week have been reported for other peptide receptors (Kent et al., 1982; Unnerstall et al., 1983; Quirion and Dam, 1986; Kiyama et al., 1987; Gonzalez
A

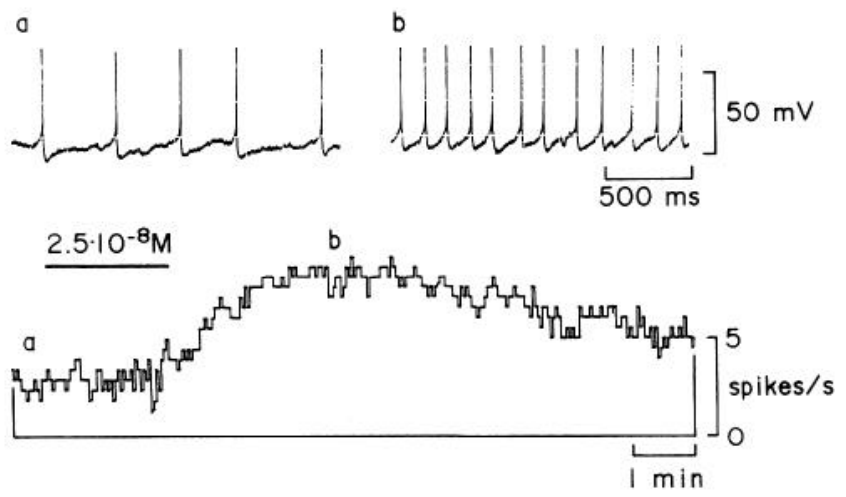

B

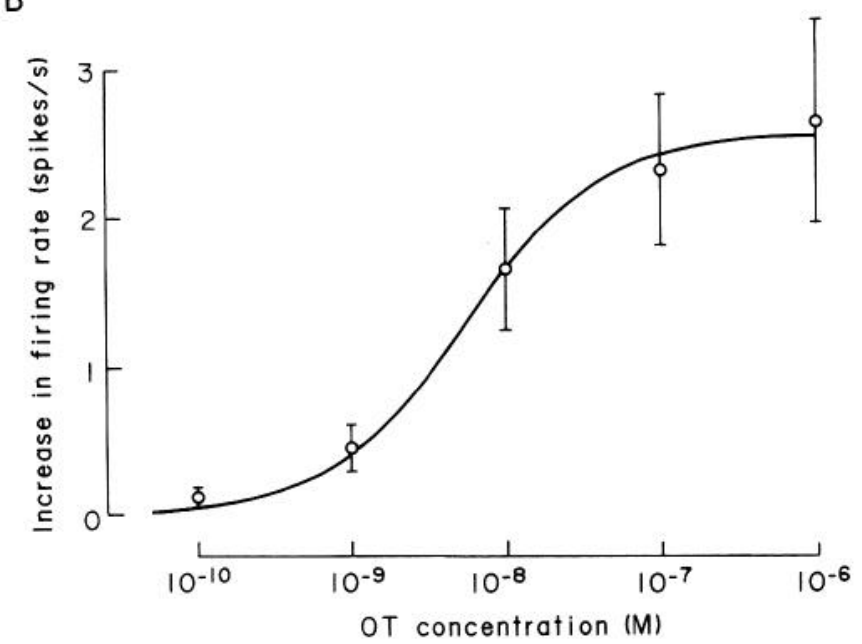

Figure 9. Stimulatory effect of oxytocin on neonatal vagal neurons. A, Intracellular recording of a vagal neuron obtained from a pup killed 20 $\mathrm{hr}$ post partum. Resting membrane potential, $-58 \mathrm{mV}$; input resistance, $280 \mathrm{M} \Omega$. Oxytocin (OT) was applied at $2.5 \times 10^{-8} \mathrm{M}$ for the period marked by the horizontal bar above the ratemeter record. Photographs of spikes taken from the oscilloscope screen at times marked $a$ and $b$ on the ratemeter are shown in the top panel. $B$, Increase in firing rate as a function of the concentration of OT for 15 cells obtained from young pups (PN3-PN12). Each neuron was tested at least for 2 concentrations. Each point represents the mean of 5-12 determinations. The height of the vertical bars above or below each point represents the SEM.

et al., 1988; Palacios et al., 1988; Tremblay et al., 1988). The transient labeling of the cingulate cortex observed by Petracca et al. (1986) with tritiated vasopressin is explained in all likelihood by binding of vasopressin to the OT receptors that we detect at this time. Indeed, the affinity of vasopressin for OT receptors is rather similar to the affinity of OT itself (Audigier and Barberis, 1985). Other events related to the maturation of the rat nervous system occur within the 3 first postnatal weeks: transient expression of neurotransmitter substances (Parnavelas and Cavanagh, 1988), neuronal multiplication in the olfactory bulb, the hippocampal dentate gyrus, the cerebellar cortex (Altman and Das, 1966; Altman, 1966, 1969), and elimination of axon collaterals (Land and Lund, 1979; O'Leary et al., 1981; Stanfield et al., 1982).

Perhaps OT receptors are maintained only in areas that are targets for OT-containing fibers in the adult brain. Receptors expressed before PN21, and not thereafter, may be concerned 
with local interactions during development that become redundant or useless later in life. OT could play a role as a trophic or differentiating factor in the shaping of functional neuronal connectivity. Such a role has been proposed for a number of neurotransmitters (Jonnson and Hallman, 1982; Zagon and McLaughlin, 1986; Brinton and Gruener, 1987; Bulloch, 1987; Hauser et al., 1987). Possibly related to this hypothesis is an observation of Shaw et al. (1984), who described a redistribution of muscarinic ACh binding sites in the cat visual cortex occurring at the time of the physiologically defined critical period (Hubel and Wiesel, 1970) and accompanied by a transient peak of acetylcholinesterase immunoreactivity in cortical layers IVVI (Bear et al., 1985).

How the expression of OT is controlled can only be conjectured. It could be regulated by trophic factors, by other transmitters, or by circulating hormones. On the other hand, in the rat, PN21 corresponds to the weaning period, and mechanisms associated with it could be involved.

\section{Late appearance of $O T$ receptors at puberty}

Some receptors appear only late, at about the time of puberty. They appear in the hypothalamic ventromedial nucleus and cell groups of the olfactory tubercle, which are regions containing a high density of cstrogen receptors in the adult (Pfaff and Kcincr, 1973). Their expression therefore probably depends upon gonadal steroids, which are synthesized in great amounts from this period onwards. This hypothesis is in agreement with the observation that estradiol increases the density of ${ }^{3} \mathrm{H}-\mathrm{OT}$ binding in the same brain areas in ovariectomized female rats (De Kloet et al., 1986; Insel, 1986). Therefore, neural circuits involving such regions may become sensitized, following the onset of puberty, to central OT via estrogen-dependent modulation of OT receptors. The influence of centrally injected OT on sexual (Caldwell et al., 1986) and maternal (Fahrbach et al., 1986) behavior further supports the view that part of the central oxytocinergic system may be involved in functions related to reproduction and in giving birth and in feeding the newborn mammal.

In summary, our results indicate that the distribution of OT binding sites undergoes major reshaping during postnatal development. In some areas, where they appear during fetal life OT binding sites remain present throughout life. In other areas, they are present in high densities in the infant but are hardly or not detectable in the adult. Finally, some areas labeled in the adult were not labeled in the infant rat. The distribution of OT binding sites evolves from an "infant pattern" to an "adult pattern" by changing rather abruptly in 2 stages, first, during the preweaning period and, second, following the onset of puberty.

\section{References}

Alstein, M., and H. Gainer (1988) Differential biosynthesis and posttranslational processing of vasopressin and oxytocin in rat brain during embryonic and postnatal development. J. Neurosci. 8: 3967-3977.

Alstein, M., M. H. Whitnall, S. House, S. Key, and H. Gainer (1988) An immunocytochemical analysis of oxytocin and vasopressin prohormone processing in vivo. Peptides 9: 87-105.

Altman, J. (1966) Autoradiographic and biological studies of postnatal neurogenesis. II. A longitudinal investigation of the kinetics migration and transportation of cells incorporating tritiated thymidine in infant rats with special reference to postnatal neurogenesis in some brain regions. J. Comp. Neurol. 128: 431-474.

Altman, J. (1969) Autoradiographic and histological studies of postnatal neurogenesis. III. Dating the time of production and onset of differentiation of cerebellar microneurons in rats. J. Comp. Neurol. 136: 269-294.

Altman, J., and G. D. Das (1966) Autoradiographic and histological studies of postnatal ncurogenesis. I. A longitudinal investigation of the kinetics migration and transformation of cells incorporating tritiated thymidine in neonate rats, with special reference to postnatal neurogenesis in some brain regions. J. Comp. Neurol. 126:337-390.

Audigier, S., and C. Barberis (1985) Pharmacological characterization of two specific binding sites for neurohypophysial hormones in hippocampal synaptic membranes of the rat. EMBO J. 4: 665-685.

Bear, M. F., F. M. Carnes, and F. F. Ebner (1985) Postnatal changes in the distribution of acetylcholinesterase in kitten striate cortex. J. Comp. Neurol. 237: 519-532.

Brinton, R. E., and R. Gruener (1987) Vasopressin promotes neurite growth in cultured embryonic neurons. Synapse $1: 329-334$

Buijs, R. M. (1983) Vasopressin and oxytocin: Their role in neurotransmission. Pharmacol. Ther. 22: 127-141.

Buijs, R. M., D. N. Velis, and D. F. Swaab (1980) Ontogeny of vasopressin and oxytocin in the fetal rat: Early vasopressinergic innervation of the fetal brain. Peptides 1:315-324.

Bulloch, A. G. M. (1987) Somatostatin enhances neurite outgrowth and electrical coupling of regenerating neurons in Helisoma. Brain Res. 412: 6-17.

Caldwell, J. D., A. J. Prange, Jr., and C. A. Petersen (1986) Oxytocin facilitates the sexual receptivity of estrogen-treated female rats. Neuropeptides 7: 175-189.

Charpak, S., W. E. Armstrong, M. Mühlethaler, and J. J. Dreifuss (1984) Stimulatory action of oxytocin on neurones of the dorsal motor nucleus of the vagus nerve. Brain Res. 300:83-89.

De Kloet, E. R., F. Rotteveel, Th. D. Voorhuis, and M. Terlou (1985) Topography of binding sites for neurohypophyseal hormones in the rat brain. Eur. J. Pharmacol. 110: 113-119.

De Kloet, E. R., D. A. M. Voorhuis, Y. Boschma, and J. Elands (1986) Estradiol modulates density of putative oxytocin receptors in discrete rat brain regions. Neuroendocrinology 44:415-421.

Elands, J., C. Barberis, and S. Jard (1988a) [ $\left.{ }^{3} \mathrm{H}\right]-\left[\mathrm{Thr}^{4}\right.$,Gly $]$ OT: A highly selective ligand for central and peripheral OT receptors. Am. J. Physiol. 254: E31-E38.

Elands, J., C. Barberis, S. Jard, E. Tribollet, J. J. Dreifuss, K. Bankowski, M. Manning, and W. H. Sawyer (1988b) [ [25I]-labelled d $\left(\mathrm{CH}_{2}\right)_{5}$

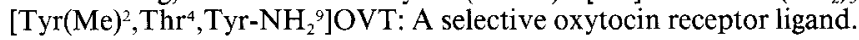
Eur. J. Pharmacol. 147: 197-207.

Fahrbach, S. F., J. I. Morell, and D. W. Pfaff (1986) Possible role for endogenous oxytocin in estrogen-facilitated maternal behavior in rats. Neuroendocrinology 40: 526-532.

Freund-Mercier, M. J., and Ph. Richard (1984) Electrophysiological evidence for facilitatory control of oxytocin neurones by oxytocin during suckling in the rat. J. Physiol. (Lond.) 352: 447-466.

Freund-Mercier, M. J., M. E. Stoeckel, J. M. Palacios, A. Pazos, J. M. Reichhart, A. Porte, and Ph. Richard (1987) Pharmacological characteristics and anatomical distribution of $\left[{ }^{3} \mathrm{H}\right]$ oxytocin-binding sites in the Wistar rat brain studied by autoradiography. Neuroscience 20 : $599-614$.

Gonzalez, B. J., P. Leroux, A. Laquerriere, D. H. Coy, C. Bodenant, and $\mathrm{H}$. Vaudry (1988) Transient expression of somatostatin receptors in the rat cerebellum. Dev. Brain Res. 40: 154-157.

Hauser, K. F., P. J. McLaughlin, and I. S. Zagon (1987) Endogenous opioids regulate dendritic growth and spine formation in developing rat brain. Brain Res. 416:157-161.

Hubel, D. H., and T. N. Wiesel (1970) The period of susceptibility to the physiological effects of unilateral eye closure in kittens. J. Physiol. (Lond.) 206: 419-436.

Insel, T. R. (1986) Postpartum increases in brain oxytocin binding. Neuroendocrinology 44: 515-518.

Jonnson, G., and H. Hallman (1982) Substance P counteracts neurotoxin damage on norepinephrine neurons in rat brain during ontogeny. Science 215: 75-77.

Kent, J. L., C. B. Pert, and M. Herkenham (1982) Ontogeny of opiate receptors in rat forebrain: Visualization by in vitro autoradiography. Dev. Brain Res. 2; 487-504.

Kiyama, H., S. I. Nagaki, S. Kito, and M. Tohyama (1987) Ontogeny of $\left[{ }^{3} \mathrm{H}\right]$ neurotensin binding sites in the rat cerebral cortex: Autoradiographic study. Dev. Brain Res. 31: 303-306.

Land, P. W., and R. D. Lund (1979) Development of the rat's uncrossed retinotectal pathway and its relation to plasticity studies. Science 205: 698-700. 
Manning, M., M. Kruszynski, K. Banakowski, A. Olma, B. Lammek, L. L. Cheng, W. A. Klis, J. Seto, J. Haldar, and W. H. Sawyer (1989) Solid phase synthesis of sixteen potent (selective and nonselective) in vivo antagonists of oxytocin. J. Med. Chem. 32: 382-390.

Mühlethaler, M., W. H. Sawyer, M. Manning, and J. J. Dreifuss (1983) Characterization of a uterine-type oxytocin receptor in the rat hippocampus. Proc. Natl. Acad. Sci. USA 80: 6713-6717.

Mühlethaler, M., S. Charpak, and J. J. Dreifuss (1984) Contrasting effects of neurohypophysial peptides on pyramidal and non-pyramidal neurones in the rat hippocampus. Brain Res. 308: 97-107.

O'Leary, D. D. M., B. B. Stanfield, and W. M. Cowan (1981) Evidence that the early postnatal restriction of the cells of origin of the collosal projection is due to the elimination of axonal collaterals rather than to the death of neurons. Dev. Brain Res. 1: 607-617.

Palacios, J. M., A. Pazos, M. M. Dietl, M. Schlumpf, and W. Lichtensteiger (1988) The ontogeny of brain neurotensin receptors studied by autoradiography. Neuroscience 25: 307-317.

Parnavelas, J. G., and M. E. Cavanagh (1988) Transient expression of neurotransmitters in the developing cortex. Trends Neurosci. 11: 92-93.

Paxinos, G., and C. Watson (1986) The Rat Brain in Stereotaxic Coordinates, 2 nd ed., Academic, Sydney.

Petracca, F. M., D. G. Baskin, J. Diaz, and D. M. Dorsa (1986) Ontogenic changes in vasopressin binding site distribution in rat brain: An autoradiographic study. Dev. Brain Res. 28: 63-68.

Pfaff, D. W., and M. Keiner (1973) Atlas of oestradiol concentrating neurons in the central nervous system of the female rat. J. Comp. Neurol. 151: 121-158.

Quirion, R., and T. V. Dam (1986) Ontogeny of substance P receptor binding sites in the rat brain. J. Neurosci. 6: 2187-2199.

Raggenbass, M., M. Dubois-Dauphin, S. Charpak, and J. J. Dreifuss (1987) Neurons in the dorsal motor nucleus of the vagus nerve are excited by oxytocin in the rat but not in the guinea pig. Proc. Natl. Acad. Sci. USA 84: 3926-3930.

Rogers, R. C., and G. E. Herman (1985) Dorsal medullary oxytocin, vasopressin, oxytocin antagonist, and TRH effects on gastric acid secretion and heart rate. Peptides 6: 1143-1148.

Shaw, C., M. C. Needler, and M. Cyander (1984) Ontogenesis of muscarinic acetylcholine binding sites in cat visual cortex: Reversal of specific laminar distribution during the critical period. Dev. Brain Res. 14: 295-299.
Sofroniew, M. V. (1985) Vasopressin, oxytocin and their related neurophysis. In Handbook of Chemical Neuroanatomy, Vol. 4: GABA and Neuropeptides in the CNS, Part I, A. Björklund and T. Hökfelt, eds., pp. 93-165, Elsevier, Amsterdani.

Stanfield, B. B., D. D. M. O'Leary, and C. Fricks (1982) Selective collateral elimination in early postnatal development restricts cortical distribution of rat pyramidal tract neurones. Nature 298: 371-373.

Suzue, T., N. Yanaihara, and M. Otsuka (1981) Actions of vasopressin, gastrin releasing peptide and other peptides on neurons of newborn rat spinal cord in vitro. Neurosci. Lett. 26: 137-142.

Switzer, R. C., J. Hill, and L. Heimer (1982) The globus pallidus and its rostroventral extension in the olfactory tubercle of the rat: A cytoand chemicoarchitectural study. Neuroscience 7: 1891-1904.

Tremblay, E., M. P. Roisin, A. Represa, C. Charriaut-Marlangue, and $Y$. Ben- $\Lambda$ ri (1988) Transient increased density of NMDA binding sites in the developing rat hippocampus. Brain Res. 461: 393-396.

Tribollet, E., C. Barberis, S. Jard, M. Dubois-Dauphin, and J. J. Dreifuss (1988a) Localization and pharmacological characterization of high affinity binding sites for vasopressin and oxytocin in the rat brain by light microscopic autoradiography. Brain Res. 442: 105-108.

Tribollet, E., M. Dubois-Dauphin, F. Loup, C. Charpak, and J. J. Dreifuss (1988b) Autoradiographic localization of oxytocin binding sites in the developing rat brain. Experientia 44: A69.

Unnerstall, J. R., M. E. Molliver, M. J. Kuhar, and J. M. Palacios (1983) Ontogeny of opiate binding sites in the hippocampus, olfactory bulb and other regions of the rat brain by autoradiographic methods. Dev. Brain Res. 7: 157-169.

Van Leeuwen, F. W., J. Van Heerikhuize, G. Van der Meulen, and P. Wolters (1985) Light microscopic autoradiographic localization of $[3 \mathrm{H}]$ oxytocin binding sites in the rat brain, pituitary and mammary gland. Brain Res. 359: 320-325.

Whitnall, M. H., S. Key, Y. Ben-Barak, K. Ozato, and H. Gainer (1985) Neurophysin in the hypothalamoneurohypophysial system. II. Immunocytochemical studies of the ontogeny of oxytocinergic and vasopressinergic neurons. J. Neurosci. 5:98-109.

Yarom, Y., M. Sugimori, and R. Llinás (1986) Ionic currents and firing patterns of mammalian vagal motoneurons in vitro. Neuroscience 16: 719-737.

Zagon, I. S., and P. J. McLaughlin (1986) Opioid antagonist-induced modulation of cerebral and hippocampal development: Histological and morphometric studies. Dev. Brain Res. 28: 233-246. 